indicate less fatigue), Pain Numerical Rating Scale (NRS) (0 [none] to 10 [worst imaginable]), Worst Joint Pain NRS (0 [none] to 10 [worst imaginable]), and the LupusPRO, a validated, lupus-specific quality of life (QoL) instrument (range 0-100, higher scores indicate better QoL).

Results: A total of 500 patients with SLE completed the survey. Patients were predominantly female (75\%), white/Caucasian (76\%), with a mean age of 42.6 years and mean disease duration of 11.1 years.

Most patients with SLE rated their overall condition as either good (38\%) or fair (31\%), with $8 \%$ rating poor and $7 \%$ excellent. Current non-biologic prescription medication use included: antimalarials $42 \%$, corticosteroids $33 \%$, immunosuppressants $33 \%$, nonsteroidal anti-inflammatory drugs (NSAID) $32 \%$, other analgesics $15 \%$ and $10 \%$ were using tofacitinib. Biologic therapies were being used by only $19 \%$, including intravenous (IV) Benlysta (37\%), subcutaneous (SC) Benlysta (25\%), rituximab (17\%), and $22 \%$ were using other biologics. Fatigue was the most commonly reported symptom (69\%), with $40 \%$ of patients ranking fatigue as their most bothersome SLE symptom. Forty eight percent of patients with current fatigue rated the severity as moderate and $33 \%$ as severe. The mean (SD) FACIT-Fatigue score was 22.9 (12.0). The next most commonly reported symptoms were joint stiffness (57\%), sleep problems (55\%), joint pain/swelling (53\%), and muscle pain (52\%). Sixty percent of patients reported experiencing pain all or most of the time over the past seven days. A total of $30 \%$ of patients with current joint pain/swelling rated it as severe, and $24 \%$ of patients with current joint stiffness rated it as severe. The mean scores for Worst pain NRS and Worst Joint Pain NRS were both 5.8 out of 10 .

The LupusPRO domains indicated by respondents as the most impacted by SLE were Emotional Health, Pain/Vitality, and Lupus Medications.

Conclusion: Fatigue, followed by pain and joint stiffness, were the most common patient-reported symptoms contributing to the overall SLE disease burden. Further research could highlight the efforts required to address the inadequacies in treatment and management of pain and fatigue in this patient population.

Disclosure of Interests: Julie Birt Shareholder of: Eli Lilly and Company, Employee of: Eli Lilly and Company, Monica Hadi: None declared, Nashmel Sargalo: None declared, Ella Brookes: None declared, Paul Swinburn: None declared, Leslie Hanrahan: None declared, Karin Tse: None declared, Natalia Bello Vega Shareholder of: Eli Lilly and Company, Employee of: Eli Lilly and Company, Kirstin Griffing Shareholder of: Eli Lilly and Company, Employee of: Eli Lilly and Company, Maria Silk Shareholder of: Eli Lilly and Company, Employee of: Eli Lilly and Company, Laure Delbecque Shareholder of: Eli Lilly and Company, Employee of: Eli Lilly and Company, Diane L Kamen Consultant of: Consulted on SLE survey development for Lilly and consulted on SLE trial protocol development for EMD Serono in 2019

DOI: 10.1136/annrheumdis-2020-eular.4190

\section{THU0254 \\ ARTICULAR INVOLVEMENT, STEROID TREATMENT AND FIBROMYALGIA ARE THE MAIN DETERMINANTS OF PATIENT-PHYSICIAN DISCORDANCE IN SYSTEMIC LUPUS ERYTHEMATOSUS}

E. Elefante $^{1,2}$, C. Tani ${ }^{1}$, F. Ferro ${ }^{1}$, C. Stagnaro ${ }^{1}$, A. Parma $^{1}$, V. Signorini ${ }^{1}$, D. Zucchi ${ }^{1}$, V. Poli ${ }^{1}$, L. Carli ${ }^{1}$, M. Mosca ${ }^{1} .{ }^{1}$ Rheumatology Unit, University of Pisa, Pisa, Italy; ${ }^{2}$ University of Siena, Department of Medical Biotechnology, Siena, Italy

Background: Remission or the lowest possible disease activity are the main targets in the management of Systemic Lupus Erythematosus (SLE). Anyway, conflicting data are present in the literature regarding the correlation between physician-driven definitions and patient perception of the disease. The discordance between patient and physician perspectives may have a negative impact on disease outcomes.

Objectives: The aim of this study was to identify the main determinants of patient-physician discordance in the evaluation of SLE and health status.

Methods: This is a cross-sectional study that enrolls patients with a diagnosis of SLE (ACR 1997 criteria). For each patient, demographics, comorbidities, treatment, clinical and laboratory data were collected. Disease activity was evaluated with the SELENA-SLEDAI score and organ damage with the SLICC/DI. Patients included have been categorized according to the following categories: remission, on or off treatment ${ }^{1}$, low disease activity (LLDAS) ${ }^{2}$ and active disease status. At enrollment, each patient completed the following PROs: SF-36, FACIT-Fatigue, LIT and SLAQ. We defined a SLAQ score $<6$, corresponding to the $25^{\circ}$ percentile of our cohort, as the cut-off value to define a low disease activity state according to the patient self-evaluation.

Results: We enrolled 259 consecutive adult SLE patients (93.05\% female, 97.2\% Caucasian, mean age $45.33 \pm 13.14$ years, median disease duration 14 years (IQR 6-21)). 208/259 patients satisfied the definition of LLDAS and among them 171 were in remission; 51/259 patients were active. No significant differences emerged as for the results of PROs between groups. Considering the subgroup of 208 patients in LLDAS, we identified 56 patients with a subjective condition of low disease activity (SLAQ $<6)$ and we defined them as "concordant"; the remaining 152 patients in LLDAS presented a subjective active disease (SLAQ $\geq 6)$ and we defined them as "discordant". Comparing these two groups, we found that "discordant" patients had more frequently ongoing and past joint involvement $(p<0.05)$ and a concomitant diagnosis of fibromyalgia $(p<0.01)$; finally, they were more frequently on glucocorticoid therapy $(p<0.01)$. "Discordant" patients showed a significantly worse quality of life, evaluated by all PROs $(p<0.0001)($ Tab 1).

Table 1. Determinants of patient-physician discordance

\begin{tabular}{|c|c|c|c|}
\hline & $\begin{array}{l}\text { Discordant patients } \\
(152 / 208)\end{array}$ & $\begin{array}{c}\text { Concordant patients } \\
\qquad(56 / 208)\end{array}$ & p-value \\
\hline $\begin{array}{l}\text { Age at enrollment } \\
\text { (years) }\end{array}$ & $47.7 \pm 13.1$ & $44.3 \pm 10.8$ & ns \\
\hline $\begin{array}{l}\text { Disease duration } \\
\text { (years) }\end{array}$ & $15.5 \pm 10.2$ & $13.8 \pm 9.2$ & ns \\
\hline SLICC-DI & $1.3 \pm 1.7$ & $0.9 \pm 1.7$ & ns \\
\hline $\begin{array}{l}\text { Ongoing joint involvement } \\
\text { (\% of patients) }\end{array}$ & $10.5 \%$ & 0 & $p<0.05$ \\
\hline $\begin{array}{l}\text { Past joint involvement } \\
\text { (\% of patients) }\end{array}$ & $70.9 \%$ & $55.3 \%$ & $p<0.05$ \\
\hline $\begin{array}{l}\text { GC therapy } \\
\text { (\% of patients) }\end{array}$ & $50 \%$ & $28.6 \%$ & $p<0.01$ \\
\hline $\begin{array}{l}\text { GC daily dose } \\
\text { (mg of prednisone) }\end{array}$ & $1.6 \pm 1.9$ & $1.1 \pm 1.9$ & $p=0.06$ \\
\hline $\begin{array}{l}\text { Fibromyalgia } \\
\text { (\% of patients) }\end{array}$ & $15.8 \%$ & $1.8 \%$ & $p<0.01$ \\
\hline PCS & $54.7 \pm 14.1$ & $65.8 \pm 20.4$ & $\mathrm{p}<0.0001$ \\
\hline MCS & $54 \pm 14.5$ & $64.3 \pm 17.7$ & $\mathrm{p}<0.0001$ \\
\hline LIT & $28.4 \pm 20.4$ & $14 \pm 16.8$ & $p<0.0001$ \\
\hline FACIT & $35.3 \pm 10.1$ & $47.3 \pm 3.6$ & $p<0.0001$ \\
\hline
\end{tabular}

Conclusion: Articular involvement, fibromyalgia and ongoing glucocorticoid treatment, even at low dose, are the major determinants of patient-physician discordance in SLE, determining a negative patient perception of health status.

\section{References:}

[1] van Vollenhoven R, et al. Ann Rheum Dis 2017 - Review. PMID 27884822

[2] Franklyn K, et al. Ann Rheum Dis 2016. PMID 26458737

Disclosure of Interests: None declared

DOI: 10.1136/annrheumdis-2020-eular.4436

\section{\begin{tabular}{|l|l}
\hline THU0255 AUTOANTIBODY PROFILE AND ETHNICITY: RISK & ACIT
\end{tabular} FACTORS FOR ACCELERATED DEVELOPMENT OF LUPUS NEPHRITIS}

M. Albirdisi ${ }^{1}$, D. D'cruz ${ }^{2}$, S. Sangle ${ }^{2}$, N. Jordan ${ }^{3} .{ }^{1}$ King Fahad Medical City, Riyadh, Saudi Arabia; ${ }^{2}$ Guys \& St Thomas Nhs Foundation Trust, Louise Coote Lupus Unit, London, United Kingdom; ${ }^{3}$ Addenbrooke's Hospital, Cambridge, United Kingdom

Background: Systemic Lupus Erythematosus (SLE) is a multisystem autoimmune disease. African ancestry is associated with an increased risk of Lupus Nephritis (LN). Anti-DNA autoantibodies play a major role in the development of LN and anti-Ro antibodies have also been implicated. McCarty et al suggested that women of African ancestry with the unusual autoantibody combination of anti-Sm, Ro \& RNP antibodies (AB) were at increased risk of developing LN (1)

Objectives: Our aim was to determine the correlation between autoantibody profile: Sm, Ro and RNP as a combination in the development of $L N$ in patients with African ancestry. We investigated time to the development of LN from SLE onset. Methods: A retrospective case-control study was conducted at Guys and S Thomas NHS Trust, London, United Kingdom.

75 patients with confirmed LN meeting the ACR classification criteria for SLE and Nephritis, were included: African $(n=35)$, Caucasian $(n=22)$ and Asian $(n=17)$ ancestry. LN patients with the combination of Sm, Ro and RNP antibodies (Group 1) were compared to LN patients without this autoantibody combination (Group 2). Demographic data, pathology results and laboratory findings were collected. Anonymised data was analyzed using Statistical Package for Social Sciences (SPSS). Left censorship bias was reduced by use of a database of confirmed LN in our cohort of patients. Research and Development Office approval was obtained for this study.

Results: There were 66 (88\%) females and $9(12 \%)$ males. The median age in Group 1 was 39 years (range 18-60), while in group 2 the median age was 45 years (range 24-64).

We stratified our population based on their antibody status: Of the $75(100 \%)$ patients, 32 (42.6\%) patients had the combination of Sm, Ro \& RNP antibodies (Group 1) while the remaining 43 (57.4\%) patients did not (Group 2). 
In Group 1, regardless of ethnicity, 29 (90.6\%) patients developed LN within 5 years or less from the onset of SLE symptoms, while the remaining $3(9.4 \%)$ developed LN after 5 years. In contrast, in Group 2, 24 (55.8\%) patients developed LN within 5 years or less while $19(44.2 \%)$ developed LN after 5 years. (P value $=0.002$ )

Further stratification was based on ethnicity and antibody $(A B)$ status to investigate the time to develop LN from SLE symptom onset: African ancestry with positive $A B$, African with negative $A B$, Asian with positive $A B$, Caucasian with positive $A B$ and Asian \& Caucasian with negative Ab. Analysis showed that of 29 (38.7\%) African ethnicity patients with the autoantibody combination, $19(65.5 \%)$, developed LN within 5 years. In comparison, 46 (61.3\%) patients, independent of ethnicity and $A B$ status, developed $L N$ after 5 years $(P$ value $=0.01)$

Conclusion: Patients with the unusual autoantibody combination of $\mathrm{Sm}$, Ro \& RNP developed LN significantly earlier than patients who did not have this combination. This autoantibody combination was significantly over represented in the African ancestry patients. Our data suggests that African ancestry patients with this autoantibody combination are at increased risk of developing LN soon after SLE symptom onset and merit close monitoring for the development of renal disease. References:

[1] McCarty GA, Harley JB, Reichlin M. A distinctive autoantibody profile in Black female patients with lupus nephritis. Arthritis \& Rheumatism. 1993; 36 : 1560-1565

Table 1.1 Ethnicity with Autoantibody status showing the rate of progression into Lupus Nephritis.

\begin{tabular}{lcccc}
\hline & & \multicolumn{2}{c}{ Duration of LN onset } & Total \\
\cline { 3 - 4 } & & $\begin{array}{c}\text { Less than 5 years } \\
\text { after SLE onset }\end{array}$ & $\begin{array}{c}\text { More than } 5 \\
\text { years after SLE } \\
\text { onset }\end{array}$ & \\
\hline Ethnicity with & African with positive & 19 & 3 & 22 \\
AB status & African with negative & 9 & 4 & 13 \\
& Asian with positive & 5 & 0 & 5 \\
Total & Caucasian with positive & 5 & 0 & 5 \\
& Other negatives & 15 & 15 & 30 \\
\hline
\end{tabular}

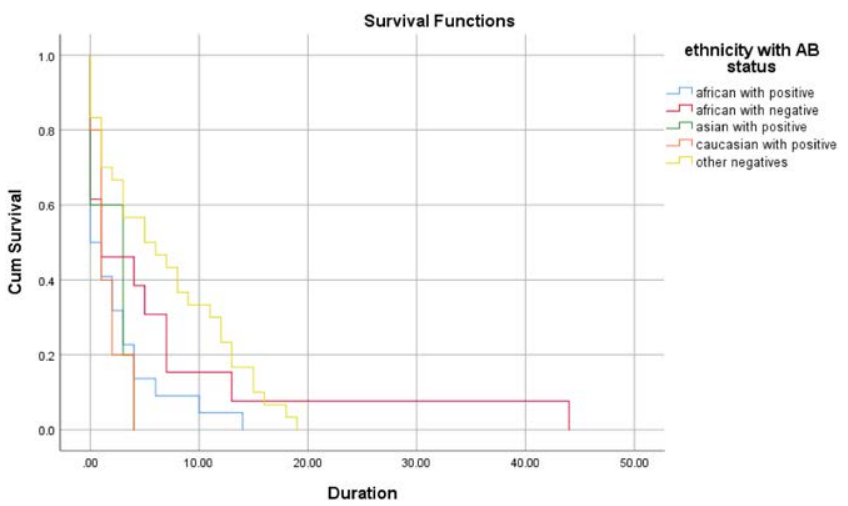

Graph 1. Ethnicity with Autoantibody status showing the rate of progression into Lupus Nephritis $(P$ value $=0.01)$

Disclosure of Interests: Majed Albirdisi: None declared, David d'cruz Grant/ research support from: GlaxoSmithKline, Shirish Sangle: None declared, Natasha Jordan: None declared

DOI: 10.1136/annrheumdis-2020-eular.4414

\section{THU0256 \\ CARDIAC INVOLVEMENT IN NEWLY DIAGNOSED SPANISH PATIENTS WITH SYSTEMIC LUPUS ERYTHEMATOSUS: DATA FROM THE RELES COHORT}

J. Álvarez Troncoso ${ }^{1}$, Á. Robles Marhuenda ${ }^{1}$, F. Mitjavila Villero ${ }^{2}$, F. J. García Hernández ${ }^{3}$, A. Marín Ballvé ${ }^{4}$, A. Castro ${ }^{5}$, G. Salvador Cervelló ${ }^{6}$, E. Fonseca ${ }^{7}$, I. Perales Fraile ${ }^{8}$, G. Ruiz-Irastorza ${ }^{9}$ on behalf of GRUPO RELES Investigators, Autoimmune Diseases Study Group (GEAS). ${ }^{1}$ Hospital Universitario La Paz, Department of Internal Medicine, Madrid, Spain; ${ }^{2}$ Hospital Universitari de Bellvitge, Department of Internal Medicine, L'Hospitalet de Llobregat, Barcelona, Spain; ${ }^{3}$ Hospital Virgen del Rocío, Department of Internal Medicine, Sevilla, Spain; ${ }^{4}$ Hospital Clínico Universitario Lozano Blesa IIIS Aragón. Grupo Autoinmunidad Clínica., Department of Internal Medicine, Zaragoza, Spain; ${ }^{5}$ Hospital Universitario Sant Joan de Reus, Department of Internal Medicine,
Tarragona, Spain; ${ }^{6}$ Hospital Universitario La Fe, Department of Internal Medicine, Valencia, Spain; ${ }^{7}$ Hospital de Cabueñes, Department of Internal Medicine, Gijón, Spain; ${ }^{8}$ Hospital Infanta Sofía, Department of Internal Medicine, Madrid, Spain; ${ }^{9}$ Hospital Universitario de Cruces, Unit of Autoimmune Diseases, Department of Internal Medicine, Baracaldo, Vizcaya, Spain

Background: Cardiac involvement is one of the most important causes of disability and mortality in patients with systemic lupus erythematosus (SLE). Transthoracic echocardiography (TTE) is a sensitive and specific technique in detecting cardiac abnormalities, particularly mild pericarditis, valvular lesions and myocardial dysfunction in SLE.

Objectives: Using data of patients from the inception cohort Registro Españo de Lupus Eritematoso Sistémico (RELES), we aimed to analyse the echocardiographic features of cardiac involvement of systemic lupus erythematosus (SLE). Methods: Prospective observational study on a multicenter Spanish inception cohort. Patients with SLE, diagnosed by the American College of Rheumatology (ACR) criteria, since January 2009, who had at least one TTE performed were selected. Demographic data, diagnostic criteria, follow-ups, treatments and SLEDAl were analyzed.

Results: We included 289 patients diagnosed with SLE with TTE performed The mean age was $40.5 \pm 1.9$ years, of which $86.9 \%$ (251) were women and $82.4 \%$ (238) Caucasian. The ACR score at diagnosis was $4.98 \pm 0.1$. Most frequent SLE manifestations were arthritis $(59.2 \%)$, photosensitivity $(49.5 \%)$, malar rash $(39.1 \%)$ and serositis $(31.1 \%)$. The main immunological findings were: ANA (97.6\%), anti-DNA (66.4\%), hypocomplementemia (58.7\%), antiphospholipid antibodies (31.5\%). One third (31.5\%) of the TTE performed were pathological. O these, $13.8 \%$ had pericardial effusion, $13.3 \%$ valvulopathy, $6.5 \%$ myocardial dysfunction, $5.2 \%$ pulmonary hypertension and $3.2 \%$ myocardiopathy. Regarding valvulopathies, $9,5 \%$ presented valvular dysfunction, $3.2 \%$ valvular thickening and $0.6 \%$ vegetation. The most frequently injured valve was the mitral $(9.1 \%)$, followed by the aortic $(2.8 \%)$. The majority of patients $(88.26 \%)$ were asymptomatic at the time of TTE. However, patients with pathological TTE had more dyspnea than those in the normal TTE group $(24.7 \%$ vs. $5.8 \%, p<0.001)$. Presenting a pathological TTE was associated with higher SLICC score $(p<0.001)$, greater number of admissions $(p<0.001)$ and mortality $(p=0.002)$. A higher SLEDAI was also associated with higher mortality $(p<0.001)$.

Conclusion: Cardiac involvement in SLE is not only related to damage accrual but can also be an early manifestation (beyond pericarditis), especially in active SLE. TTE assessment should be considered as a part of routine examination for SLE due to the high prevalence of heart disease even in asymptomatic patients.

\section{References:}

[1] Doria A, laccarino L, Sarzi-Puttini P, Atzeni F, Turriel M, Petri M. Cardiac involvement in systemic lupus erythematosus. Lupus. 2005;14(9):683-686.

[2] Chen J, Tang Y, Zhu M, Xu A. Heart involvement in systemic lupus erythematosus: a systemic review and meta-analysis. Clin Rheumatol. 2016; 35(10):2437-2448.

Disclosure of Interests: Jorge Álvarez Troncoso: None declared, Ángel Robles Marhuenda: None declared, Francesca Mitjavila Villero: None declared, Francisco José García Hernández: None declared, Adela Marín Ballvé: None declared, Antoni Castro Consultant of: Actelion pharmaceuticals, GSK, MSD., Gonzalo Salvador Cervelló: None declared, Eva Fonseca: None declared, Isabel Perales Fraile: None declared, Guillermo Ruiz-Iras torza: None declared DOI: 10.1136/annrheumdis-2020-eular.1633

\section{THU0257 ESTIMATED 10-YEARS CARDIOVASCULAR RISK IN SYSTEMIC LUPUS ERYTHEMATOSUS PATIENTS: PRELIMINARY RESULTS FROM THE "CARDIOVASCULAR OBESITY AND RHEUMATIC DISEASE (CORDIS)" STUDY GROUP OF THE ITALIAN SOCIETY OF RHEUMATOLOGY.}

F. Cacciapaglia ${ }^{1}$, A. Manfredi ${ }^{2}$, G. Erre ${ }^{3}$, E. Bartoloni Bocci ${ }^{4}$, G. Sakellariou ${ }^{5}$ O. Viapiana ${ }^{6}$, S. Colella ${ }^{1}$, A. Abbruzzese ${ }^{1}$, M. Fornaro ${ }^{1}$, G. Cafaro ${ }^{4}$, M. A. Fenu ${ }^{7}$, B. L. Palermo ${ }^{5}$, M. Dessì , A. Palermo ${ }^{2}$, A. Giollo ${ }^{8}$, E. Gremese ${ }^{9}$, F. R. Spinelli ${ }^{10}$ F. Atzeni ${ }^{11}, \mathrm{M}$. Piga ${ }^{7}$ on behalf of "Cardiovascular Obesity and Rheumatic DISease (CORDIS)" Study Group of the Italian Society of Rheumatology. ${ }^{1}$ Rheumatology Unit, Department of Emergency and Organs Transplantation - University and AOU Policlinico of Bari, Bari, Italy; ${ }^{2}$ Rheumatology Unit, University of Modena and Reggio Emilia, Azienda Ospedaliero-Universitaria Policlinico di Modena, Modena, Italy; ${ }^{3}$ UOC Reumatologia, Specialità Mediche - Azienda Ospedaliero Universitaria di Sassari, Sassari, Italy; ${ }^{4}$ Rheumatology Unit, Department of Medicine, University of Perugia., Perugia, Italy; ${ }^{5}$ Division of Rheumatology, University of Pavia, IRCCS Policlinico San Matteo Foundation, Pavia, Italy; ${ }^{6}$ Rheumatology Unit, University of Verona, Verona, Italy; ${ }^{7}$ Rheumatology Unit, Department of Medical Sciences - University and AOU Policlinico of Cagliari, Cagliari, Italy; ${ }^{8}$ Rheumatology Unit, University of Verona, 